This item was submitted to Loughborough's Research Repository by the author.

Items in Figshare are protected by copyright, with all rights reserved, unless otherwise indicated.

\title{
Advanced reliability analysis of Polymer Electrolyte Membrane Fuel Cells using Petri-Net analysis and fuel cell modelling techniques
}

PLEASE CITE THE PUBLISHED VERSION

http://dx.doi.org/10.1016/j.ijhydene.2015.01.154

\section{PUBLISHER}

(C) Elsevier

VERSION

AM (Accepted Manuscript)

\section{PUBLISHER STATEMENT}

This work is made available according to the conditions of the Creative Commons Attribution-NonCommercialNoDerivatives 4.0 International (CC BY-NC-ND 4.0) licence. Full details of this licence are available at: https://creativecommons.org/licenses/by-nc-nd/4.0/

\section{LICENCE}

CC BY-NC-ND 4.0

\section{REPOSITORY RECORD}

Whiteley, Michael, Ashley Fly, Johanna M. Leigh, Sarah J. Dunnett, and Lisa M. Jackson. 2015. "Advanced Reliability Analysis of Polymer Electrolyte Membrane Fuel Cells Using Petri-net Analysis and Fuel Cell Modelling Techniques". figshare. https://hdl.handle.net/2134/17306. 


\title{
Advanced reliability analysis of Polymer Electrolyte Membrane Fuel Cells using Petri-Net analysis and Fuel Cell modelling techniques.
}

\author{
Michael Whiteley*, Ashley Fly, Johanna Leigh, Sarah Dunnett, Lisa \\ Jackson \\ Aeronautical $\& 3$ Automotive Engineering Department, Loughborough University, \\ Loughborough, Leicestershire, LE11 3TU
}

\begin{abstract}
Reliability issues with fuel cells have held back the commercialisation of this new technology, and as such are required to be studied further. Current reliability standards for automotive applications require an operational lifetime of 150,000 miles or 5,000 hours. These standards are hard to achieve; therefore in depth reliability analysis and degradation studies can help allude towards the key areas of improvement in fuel cell technology to meet these standards.

Previous Failure Mode and Effect Analysis (FMEA) work has shown that the multi-component system of a Polymer Electrolyte Membrane Fuel Cell (PEMFC) is inherently complex. Dependencies exist between multiple failure modes which discounts Fault Tree Analysis (FTA) as a feasible reliability modelling technique. Therefore, in this study, Petri-Net simulation and fuel cell modelling techniques have been adopted to develop an accurate degradation model. Operational parameters such as water content, temperature and current density and their effects on the occurrence of failure modes can be modelled through this technique. The work will improve previous fuel cell reliability studies by taking into consideration; operating parameters (water content, temperature), fuel cell voltage based on demand (drive cycles) and dependencies between failure modes.
\end{abstract}

Email address: m.whiteley@lboro.ac.uk (Michael Whiteley)

${ }^{1} 07896009227$ 
Keywords: PEMFC, reliability, degradation, petri-net, analysis

\section{Introduction}

\subsection{Why Hydrogen Fuel Cells?}

In recent years, climate change and sustainability issues have become more poignant and further discussed. This is due to the evidence that points towards an anthropogenic source of climate change (Soloman et al. [1]). Man-made activities contribute towards climate change through Greenhouse Gas (GHG) emissions, which include; carbon dioxide $\left(\mathrm{CO}_{2}\right)$, methane $\left(\mathrm{CH}_{4}\right)$ and nitrous oxide $\left(\mathrm{N}_{2} \mathrm{O}\right)$ among others.

The UK emitted 549.3 Million tonnes of Carbon Dioxide equivalent $\left(\mathrm{MtCO}_{2} \mathrm{e}\right)$ in 2011 (Dept. for Transport. [2]) and $122.2 \mathrm{MtCO}_{2} \mathrm{e}$ was due to the transport industry, with $74 \%$ of this figure due to cars, taxis and buses (DECC. [3]). Other countries have also pledged to tackle climate change, with the US president stating that the US will reduce $\mathrm{CO}_{2}$ emissions $17 \%$ from 2005 levels by $2020,42 \%$ by 2030 and finally $83 \%$ by 2050 .

Not only are GHGs negatively affecting the atmosphere, energy prices are set to continue to rise at alarming rates (BERR. [4]), which could dramatically affect the UKs energy system and energy security concerns. Due to the aforementioned negative environmental impacts of emissions from fossil fuel energy sources and concerns with energy prices and security, this figure needs to be dramatically reduced not only to meet government targets, but for the health of the biosphere.

Hydrogen fuel cells are a zero-emission energy conversion and power generation device. They combine Hydrogen $\left(\mathrm{H}_{2}\right)$ and Oxygen $\left(\mathrm{O}_{2}\right)$ gases to form water $\left(\mathrm{H}_{2} \mathrm{O}\right)$, heat and electrical energy. If the $\mathrm{H}_{2}$ is sourced from renewable means, such as electrolysis of $\mathrm{H}_{2} \mathrm{O}$ from wind turbine electricity, the whole process is zero emissions in use. With this in mind, hydrogen fuel cells have the potential to mitigate climate change and energy security concerns.

\subsection{The Polymer Electrolyte Membrane Fuel Cell}

Out of the five main types of fuel cell, the PEMFC has been singled out as the most applicable to automotive applications. This is due to its low operating temperature and rapid start-up times.

There are three main hurdles to the commercialisation of PEMFCs; Cost, Infrastructure and Reliability. Currently PEMFCs in automotive applications need to meet the United States (US) Department of Energy (DoE) 
standards of 5000 hours lifetime with a performance drop of no more than $5 \%$ over that time, with the Japanese and European standards being similar (Borup, et al.[5]). However, modern day PEMFC systems struggle to reach these targets due to unforeseen degradation of the membrane, Catalyst Layer (CL), Gas Diffusion Layer (GDL) and Bipolar Plate (BIP) components, contributing towards a reduction in performance.

\section{3. $P E M F C$}

PEMFCs can suffer three main types of degradation during the operating lifetime; chemical, thermal and mechanical degradation. These failure mechanism classes can stem from numerous individual failure modes that the PEMFC can experience. An example of a failure mode linked to chemical degradation is illustrated in section 1.3.1.

\subsubsection{Chemical Degradation}

An example of chemical degradation is hydroxyl $(\mathrm{OH})$ and hydroperoxy $(\mathrm{OOH})$ radical attack. $\mathrm{OH}$ and $\mathrm{OOH}$ radicals are caused by the chemical changes brought around due to $\mathrm{H}_{2} \mathrm{O}_{2}$ (peroxide) presence. As such, $\mathrm{H}_{2} \mathrm{O}_{2}$ formation from its two main pathways (diffusion of gasses through membrane and electron reduction) can lead on to a chemical attack of the Polytetrafluoroethylene (PTFE) based membrane and areas of the CL and GDL.

To further explain the pathways, LaConti, et al. [6] proposed a method of production of radicals which occurs due to the diffusion of gasses through the membrane.

$$
\begin{gathered}
\mathrm{H}_{2} \rightarrow 2 \mathrm{H} \cdot \\
\mathrm{H} \cdot+\mathrm{O}_{2} \rightarrow \mathrm{HO}_{2} \cdot \\
\mathrm{HO}_{2} \cdot+\mathrm{H} \cdot \rightarrow \mathrm{H}_{2} \mathrm{O}_{2} \\
\mathrm{H}_{2} \mathrm{O}_{2}+\mathrm{M}_{2}^{+} \rightarrow \mathrm{M}_{3}^{+}+\cdot \mathrm{OH}+\mathrm{OH}^{-} \\
\cdot \mathrm{OH}+\mathrm{H}_{2} \mathrm{O}_{2} \rightarrow \mathrm{H}_{2} \mathrm{O}+\mathrm{HO}_{2} .
\end{gathered}
$$

Equations 1.5 show the stages of how radicals are a product of $\mathrm{H}_{2} \mathrm{O}_{2}$ production which occurs under normal operating conditions and membrane health. Therefore $\mathrm{H}_{2} \mathrm{O}_{2}$ needs to be included as the basic event leading to radical formation. 
Peroxide can form in another way, by a two electron reduction of $\mathrm{O}_{2}$ pathway (Pozio, et al. [7]) explained in Equation 6.

$$
\mathrm{O}_{2}+2 \mathrm{H}^{+}+2 \mathrm{e}^{-} \rightarrow \mathrm{H}_{2} \mathrm{O}_{2}
$$

The way in which radical and peroxide attack affects the degradation of the cell is through the thinning of the membrane over time. This is achieved by end-group unzipping and chain scission processes, actively eating away at the chemical bonds of the PTFE based membrane.

\section{Reliability Analysis of PEMFCs}

Reliability analysis of PEMFCs is still in its infancy and needs to be further developed to advance the understanding of degradation mechanisms and lifetime of PEMFCs. Previous work includes a failure mode identification and FTA of a general PEMFC by Rama, et al. 88. Additionally, a more recent FTA work was presented by Placca \& Kouta [9], looking at the failure modes that could cause PEMFC degradation.

The existing reliability work has proven to be a good start with understanding PEMFC degradation and failure. However, the latest work by Whiteley, et al.10] [11] has identified that there were areas that could be improved and developed to further the reliability and degradation field of PEMFC research. These enhancements, including FMEA \& FTA are summarised in section 2.1 and 2.2 respectively.

\subsection{FMEA}

A FMEA was performed to systematically evaluate the potential failures that can occur in a PEMFC system, and their effects on the operation of the system. This work extended the previous work by Rama, et al. [8], fully outlining all of the failure modes and their effects in a PEMFC assembly.

The FMEA table consists of the identification of the physical component of the PEMFC being analysed, followed by a brief description of its function. The failure modes that can be experienced in this area are then listed, detailing the effects that this failure mode has. The local effect is the contained effect of the failure mode, whereas the system effect is how the failure mode will affect the overall operation of the entire system. Failure detection methods are listed for more details on how to distinguish these failures, whether it be in-situ or ex-situ. Mitigation strategies are listed where previous work 
has identified a way to reduce or mitigate against these failure modes. Any poignant remarks are listed that may help further the understanding of any of the previously highlighted points, followed by any key relationships between the listed failure mode, and any other failure mode in the system that is being analysed. Finally the source of the failure mode information is listed for integrity.

This work filled a gap in current PEMFC degradation literature by providing a comprehensive list of component and system level failure modes that a PEMFC can experience. The outcome was identification of 21 components failure modes, resulting in 39 different potential system failure effects.

\subsection{FTA}

The existing work in FTA for PEMFCs by Placca \& Kouta [9] showed 37 individual basic events that could lead to the top-level intermediate events of Membrane Degradation, Catalyst Layers Degradation and Gas Diffusion Layers Degradation. These three intermediate events lead on to the overall top event of Degradation of the Cell. The work harboured key areas that were flagged for improvement, to increase the accuracy of the FTA model. A new state-of-the-art FTA was undertaken by Whiteley, et al. [10] [11] to rectify the issues arisen in the existing work, which saw a complete re-draw of the failure logic for a PEMFC. Areas that needed attention were; Top Event Ambiguity, BIP Omission, Ambiguity of Intermediate Events, Lack of Standardised Data, Errors in Proposed Degradation Rates and an overall re-think of the failure logic.

The failure modes identified and developed to advance the FTA PEMFC

work are presented in Table 1, where failure modes listed in bold font are carried over from the existing work by Placca \& Kouta [9]: 


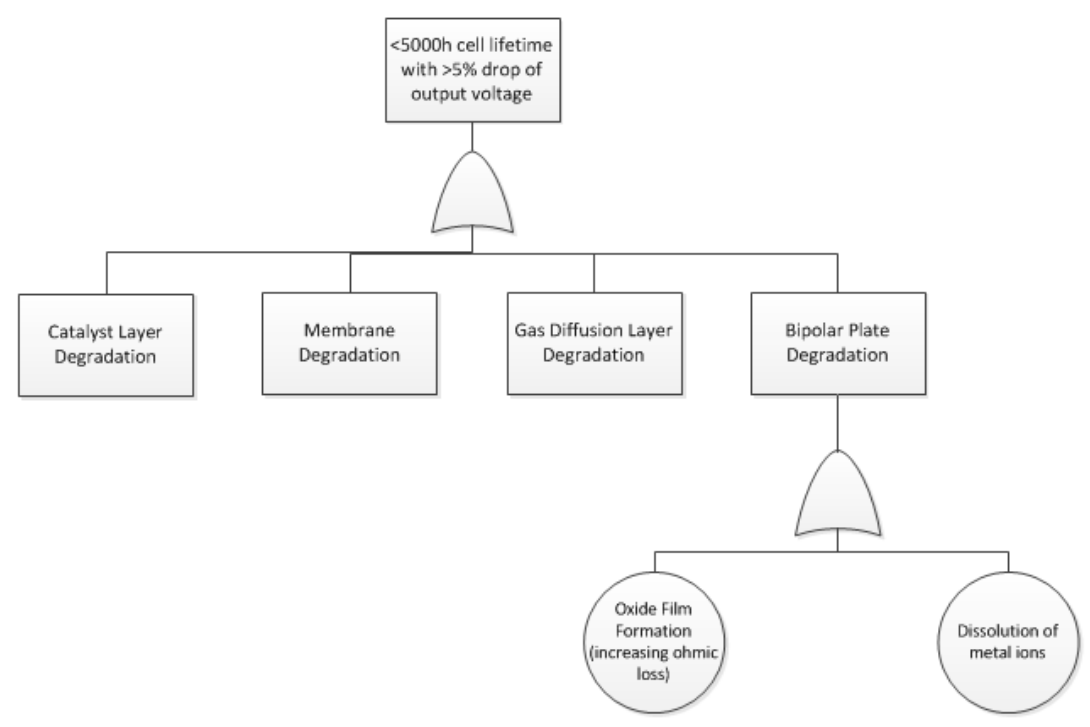

Figure 1: Proposed Change to 'Global' Tree

The FTA work has provided a clear failure logic structure for a PEMFC, identifying the key basic events that contribute to the overall degradation of PEMFC performance. However, one of the main weaknesses of the FTA approach is that it assumes independent failure event occurrence. Hence Petri-Net simulation has been adopted to address this issue.

\section{Petri-Net Simulation}

Petri-Net simulation is based upon a graphical process of representing component relationships, conditions and events. It can be used to model and analyse dynamic behaviours of systems taking into account relationships and dependencies which FTA cannot.

Petri-Nets are comprised of two main symbols; 'places' $(P)$ and 'transitions' $(T)$. These two nodes are connected by arrows known as 'Arcs' $(A)$, which show the direction of flow of 'tokens'. Tokens are used to describe the state of the system, and are used to mark/enable a place as in Figure 2. 


\begin{tabular}{l}
\hline Basic Events - Membrane \\
\hline Incorrect BIP torque \\
Polymer membrane 'creep' \\
Microcrack Fracture \\
OH and OOH radicals \& $\mathbf{H}_{2} \mathrm{O}_{2}$ contamination to PTFE \\
Presence of foreign cationic ions: Dissolution of metal ions from BIP - \\
- corrosion / Contaminant from humidifier/air pipe/gas impurity \\
Ice Formation \\
Fatigue from Relative Humidity and Temperature cycling \\
Excessive Heat Degradation \\
Flooding \\
\hline Basic Events - Catalyst \\
\hline Pt Agglomeration and particle growth \\
Pt Elemental loss \\
Pt Migration \\
Pt Contamination \\
Startup/Shutdown Cycling \\
Flooding \\
Ice Formation \\
\hline Basic Events - Gas Diffusion Layer \\
\hline OH Radicals \\
Flooding \\
Ice Formation \\
\hline Basic Events - Bipolar plate \\
\hline Oxide Film Formation \\
Corrosion leading to release of multivalent cations \\
\hline
\end{tabular}

Table 1: List of Basic Events 


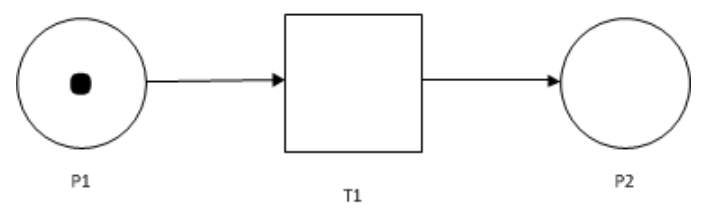

Figure 2: Example, simple Petri-Net

Figure 2 shows a simple Petri-Net that has place one enabled (P1 containing a token). The transition (T1) will fire based on criteria that could range from time intervals to probability. Once the criteria are met, the transition will take the one token from P1 and place it into P2, denoting a new state.

P, T and A can be defined as by Liu \& Chiou [12]:

$$
\mathrm{P}=\left\{\mathrm{P}_{i} \mid \mathrm{P}_{i} \text { is a place, } 1 \leq \mathrm{i} \leq \mathrm{I}\right\},
$$

Where $\mathrm{I}$ is a positive integer

$\mathrm{T}=\left\{\mathrm{T}_{i} \mid \mathrm{T}_{i}\right.$ is a transition, $\left.1 \leq \mathrm{i} \leq \mathrm{I}\right\}$,

$\mathrm{A} \subseteq(\mathrm{P} \times \mathrm{T}) \cup(\mathrm{T} \times \mathrm{P})$

\subsection{Benefits of Petri-Net Simulation}

Petri-Net simulation offers significant advantages over FMEA and FTA. FMEA is more geared towards the analysis of individual failure modes, and doesn't look at the interactions between a group of failure modes. FTA can look at the relationships between failure modes in a graphical manor, however the technique cannot take into account dependencies between failure modes.

Petri-Net simulation can take into account dependencies, and has been chosen to analyse the failure characteristics of a PEMFC.

\subsection{Existing Work in the Literature}

There is currently only one example of Petri-Net use for reliability analysis of PEMFCs from Wieland, et al. [13] and is a good start to develop reliability analysis in this field. However, the model could be further developed to accurately represent all of the previously identified failure modes from FMEA and FTA work presented by Whiteley, et al. [10] [11].

The existing work in the literature has an initial place which denotes the operational state of a PEMFC. The model can fire through five main transitions; Degradation, Spontaneous event, Reversible event, Repair and 
Breakdown. All transitions are based upon degradation rates taken from the literature or the authors own assumptions. These rates are selected using the normal distribution based upon mean, lower limit and upper limits, again assumed by the authors.

\subsubsection{Limitations with Failure Rates/Probabilities Used}

Using the normal distribution is a limitation when analysing PEMFCs. Components don't share characteristics with normal distribution probability theory, rather components ageing in a system share more characteristics with the Weibull distribution, owing to the 'bathtub curve' (Figure 3).

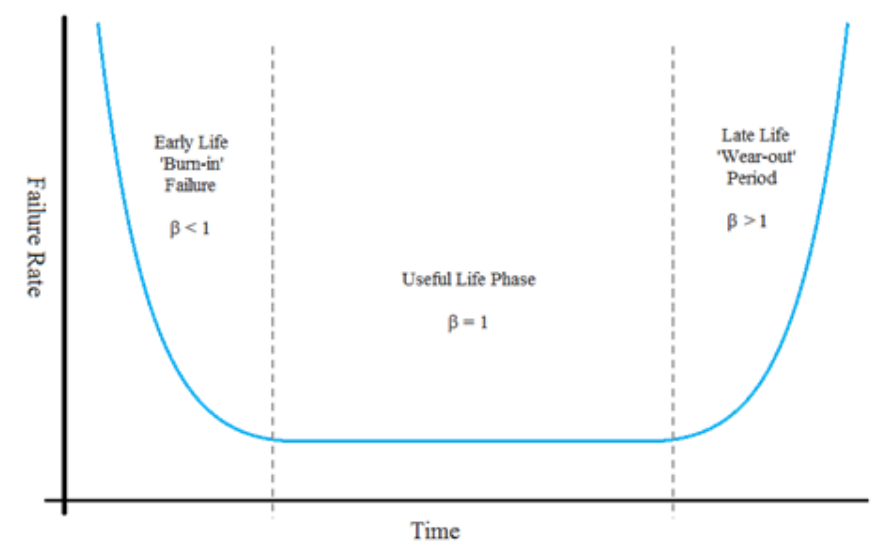

Figure 3: Component 'Bathtub Curve'

The Weibull shape parameter ' $\beta$ ' is reflective of what stage the component is in due to the lifetime of the component. This shape parameter can be changed dependent upon the failure mode in question. That is to say that an early life failure mode such as early life Platinum (Pt) agglomeration would have a shape parameter of less than one. Whereas failure due to creep under normal conditions (that can take upwards of 5000 hours to cause a failure) would use a shape parameter of more than one.

\subsubsection{Limitations with Parameters Used}

The failure parameters used can be considered to be vague and limited in number for an accurate degradation model of a PEMFC. In the work by Wieland, et al[13], degradation transition severity is calculated from a normal distribution using the Natural Aging parameter from 1 to $70 \mu \mathrm{Vh}^{-1}$ (microvolts per hour). This assumes that degradation is a simple process and can be 
derived from lifetime test degradation rates. However due to the inherently complex system of a PEMFC, degradation relationships can interact and harbour dependencies that can alter the overall lifetime, based upon their interaction and operating conditions (Whiteley, et al. [10]). Spontaneous and reversible parameter use could also be optimised. Wieland, et al.[13] suggest that random variables are used to select if one of the spontaneous events or reversible events are occurring. However 'High temperature operation and Start below $0^{\circ} \mathrm{C}$ (SBZ)' could never occur together.

The authors themselves acknowledged the limitations of their model:

'there is a lot of simplification done to get this first model. For example, spontaneous events occur independently of the stack state and degradation is steady, instead of increasing at certain times such as summer or winter'

Wieland, et al.[13] pp38

\section{Proposed Model}

The proposed work in this paper seeks to enhance the capabilities of the Petri-Net approach for PEMFC degradation modelling. The overall 'Global' Petri-net is presented in Figure 4.

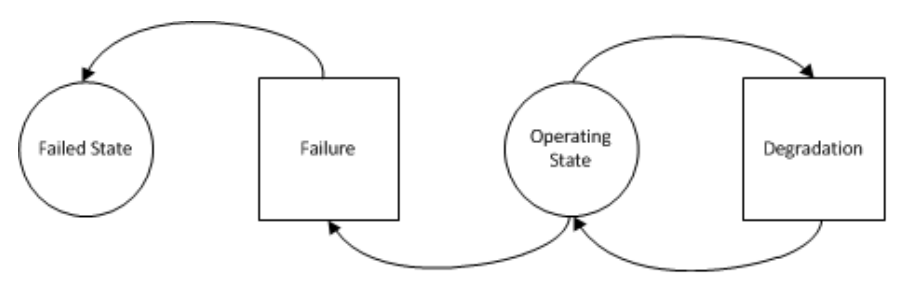

Figure 4: Global Petri-Net

There are two global states 'Operating State' and 'Failed State', The 'Operating State' is initially set at 100\% health of the PEMFC and fires through the 'Degradation' transition on every time-step. Contained within the degradation transition, are separate Petri-Nets based upon the knowledge gained through FMEA and FTA as discussed in 4.1. Each failure mode has a relationship Petri-Net to explain its logic, and how it might interact with other failure modes in the system. 
The 'Failure' transition will fire based upon the criteria of unacceptable system performance. This is set at a lifetime of less than 5000 hours with more than a $5 \%$ drop in cell performance over that time as per the US DoE target. If this target threshold is exceeded, the transition will fire into the 'Failed' state.

\subsection{Degradation Modules}

Each failure mode previously identified in the FMEA and FTA has a Petri-Net attributed to it, which shows the logic contributing towards its activation. A total of 21 Petri-Net modules have been created however only one is discussed here for brevity. Figure 5 shows an example of a Petri-Net module for a given failure mode: ' $\mathrm{H}_{2} \mathrm{O}_{2}$ Degradation'.

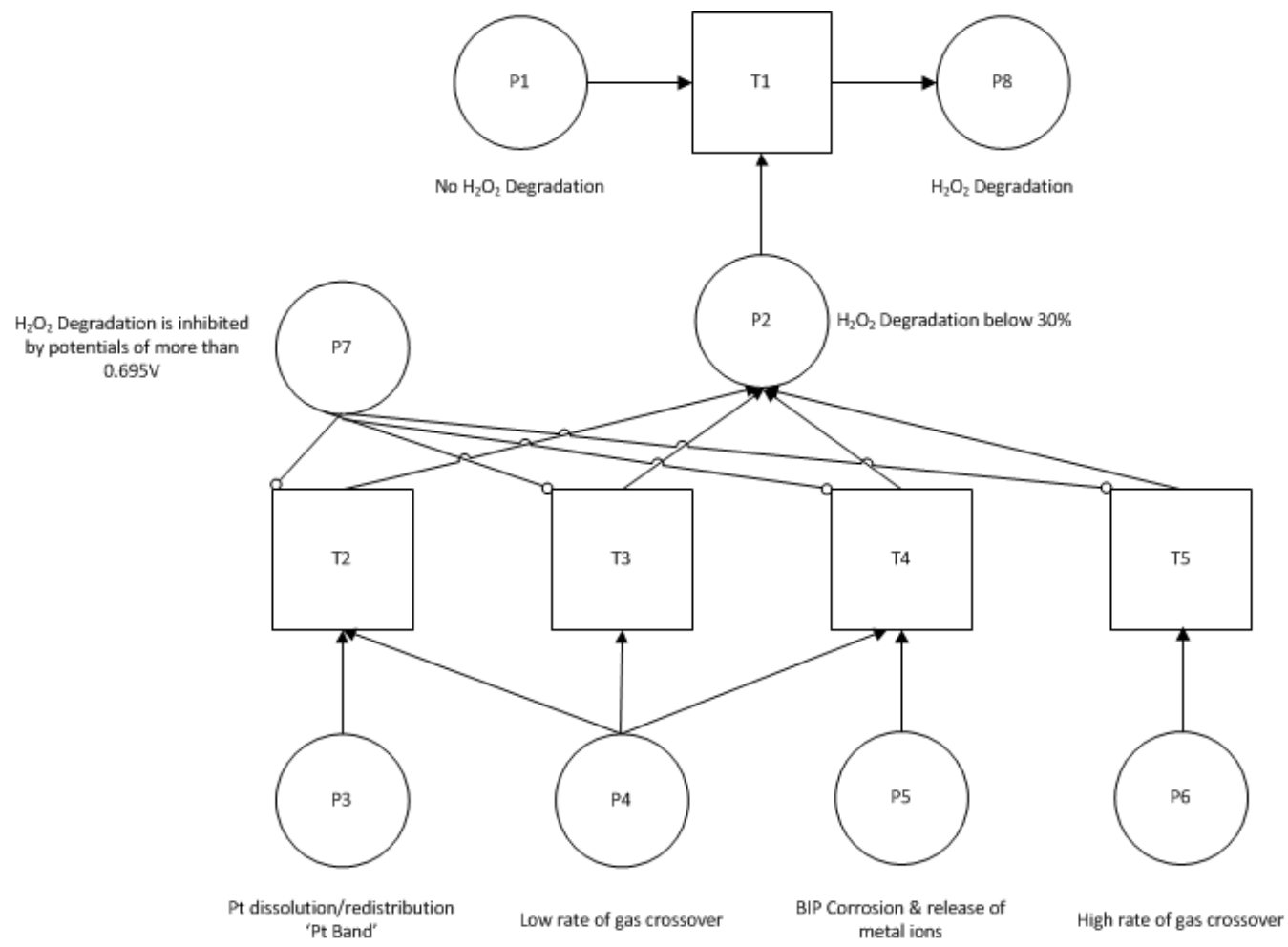

Figure 5: Example Petri-Net for $\mathrm{H}_{2} \mathrm{O}_{2}$ Degradation

$P 1$ is the initial place, and is enabled with a token on the first running of the model. It is indicative of a healthy PEMFC and is enabled from the first running of the model, with no $\mathrm{H}_{2} \mathrm{O}_{2}$ degradation. T1 can only fire when 
there is a token in $P 2$ and $P 1$ at the same time. $P 2$ is used to indicate a state of $\mathrm{H}_{2} \mathrm{O}_{2}$ degradation, agglomerating the lower level transitions. This is for the integrity of the transition logic. The firing of this transition would enable $P 8$, indicating a state of $\mathrm{H}_{2} \mathrm{O}_{2}$ degradation, and would have an output affecting the performance of the PEMFC and potentially linking into another Petri-Net module. There are a number of contributors to $P \mathcal{2}$, stemming from places P3 'Pt dissolution/redistribution 'Pt Band", P4 'Low rate of gas crossover', $P 5$ 'BIP corrosion \& release of metal ions' and $P 6$ 'High rate of gas crossover'. $P 3$ is enabled by an interaction from a separate Petri-Net module, and indicates the presence of $\mathrm{Pt}$ which acts as a catalyst for $\mathrm{H}_{2} \mathrm{O}_{2}$ formation (LaConti, et al.[6]) shown in Equations 7.9.

$$
\begin{gathered}
\mathrm{H}_{2}+\mathrm{Pt} \rightarrow \mathrm{Pt}-\mathrm{H} \\
\mathrm{Pt}-\mathrm{H}+\mathrm{O}_{2} \rightarrow \cdot \mathrm{OOH} \\
\cdot O O H+\mathrm{Pt}-\mathrm{H} \rightarrow \mathrm{H}_{2} \mathrm{O}_{2}
\end{gathered}
$$

Therefore for 'T2' to fire, 'P3' and 'P4' need to be enabled. This would show that there is gas crossover and a free $\mathrm{Pt}$ presence to cause a rate of formation of $\mathrm{H}_{2} \mathrm{O}_{2}$.

As has been previously mentioned in Equations $1,6, \mathrm{H}_{2} \mathrm{O}_{2}$ can form from the crossover of the reactant gasses through the membrane. Thus for a given rate of gas crossover, a corresponding rate of $\mathrm{H}_{2} \mathrm{O}_{2}$ formation is attributed. This enables the Petri-Net modelling of 'T3' and ' $\mathrm{T} 5$ ' firing and a corresponding degradation of PEMFC overall performance. Consequently if ' $\mathrm{P} 6$ ' is enabled, 'T5' will fire, placing a token in 'P2', and if 'P4' is enabled, 'T3' will fire a token into 'P2'.

Pozio, et al.[7] also showed that the presence of $\mathrm{Fe}_{2}^{+}$and $\mathrm{Cu}_{2}^{+}$(Iron and Copper ions) released from BIP corrosion greatly accelerate the degradation due to $\mathrm{H}_{2} \mathrm{O}_{2}$ formation when there is gas crossover. Therefore a separate rate is associated with ' $\mathrm{T} 4$ '.

'P7' is an inhibitor and serves to prevent the transition of 'T2', 'T3', 'T4' \& 'T5'. Borup, et al. [5] state that the potential for $\mathrm{H}_{2} \mathrm{O}_{2}$ formation $\left(\mathrm{E}^{o}\right.$ $\mathrm{H}_{2} \mathrm{O}_{2}$ ) is equal to $0.695 \mathrm{~V}$, and that any potential greater than this would inhibit the formation of $\mathrm{H}_{2} \mathrm{O}_{2}$ in the PEMFC. 


\subsection{Petri-Net Firing}

The firing of the Petri-Net uses the following equation:

$$
M_{n}=M_{0}+A^{T} \sum
$$

Where $M_{n}$ is the final marking, $M_{0}$ is the initial marking, $A^{T}$ is the incidence matrix for the module, and $\sum$ is the transition firing count vector. The relationship between $A^{T}$ and $\sum$ is summarised in Equation 11 .

$$
A^{T} \sum=\Delta M=M_{n}-M_{0}
$$

For each individual Petri-Net module contained within the 'Degradation' transition of the global Petri-Net, there is a corresponding incidence matrix as in Equation 12 for $\mathrm{H}_{2} \mathrm{O}_{2}$ degradation.

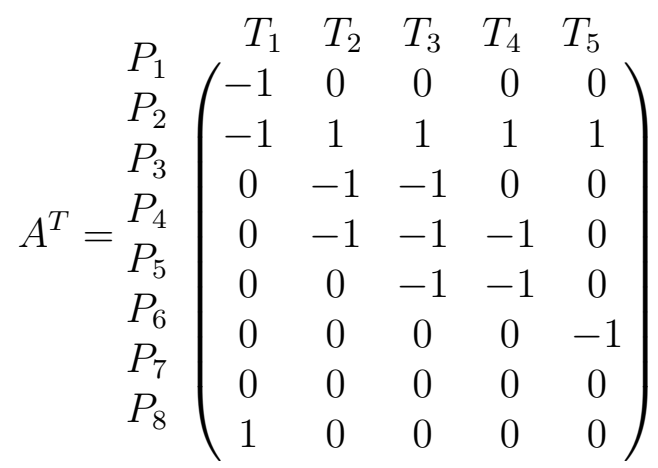

The logic behind each transition from place to place is noted in each $A^{T}$ matrix for each module. A ' -1 ' indicates the taking of a token from a place, and a ' 1 ' indicates the placing of a token into that place.

\subsection{Fuel Cell Model}

A lumped parameter PEMFC model developed by Fly \& Thring [21] is used to validate voltage degradation predictions against observed degradation from the literature. Additionally it can be used to integrate the degradation model and therefore have a more accurate relationship between degradation and operational performance. The fuel cell model is initially run to ascertain the operating conditions of the cell. These data are then used by the PetriNet to model the degradation based upon the fuel cell's conditions. 


\subsection{Summary of the Petri-Net Model}

The Petri-Net degradation model developed in this work is a comprehensive model of the interactions between the previously identified failure modes in a PEMFC of standard construction (PTFE based membrane, Carbon/Pt catalyst, steel BIP, carbon GDL). The individual modules range from relatively simple relationships with 2-3 places and a low number of transitions, to larger modules with 8 places and 8 transitions. It contains 21 separate modules that interact to both; deliver a voltage degradation value, and further interact with other failure modes. However, if further interactions or modules are discovered that need to be added, the Petri-Net model can easily facilitate this occurrence, with a simple addition to the script files. The

model parameters and degradation rates for failure modes are listed in tables $2 \& \&$. 


\begin{tabular}{ll}
\hline Cell Performance Model Parameter & Value \& Unit \\
\hline Fuel cell rated power & $50 \mathrm{~kW}$ \\
Maximum system efficiency & $56 \%$ \\
System efficiency @ 50\% load & $50 \%$ \\
Number of cells & 360 \\
Cell active area & $200 \mathrm{~cm}^{2}$ \\
Cathode stoichiometry & 2.5 \\
Anode stoichiometry & 1.03 \\
Stack mass & $30 \mathrm{~kg}$ \\
Stack specific heat & $3.5 \mathrm{~kJ} / \mathrm{kgK}$ \\
Stack cathode volume & $0.01 \mathrm{~m}^{3}$ \\
Stack dimensions & $20 \times 20 \times 60 \mathrm{~cm}^{3}$ \\
Ambient humidity & $70 \%$ \\
Membrane thickness & $100 \mu \mathrm{m}$ \\
Internal current density & $1.5 \times 10^{-4} \mathrm{~A} / \mathrm{cm}^{2}$ \\
Mass transport coefficient & $3 \times 10^{-4}$ \\
Exchange current density & $3.2 \times 10^{-8} \mathrm{~A} / \mathrm{cm}^{2}$ \\
Stack surface heat transfer coefficient & $5 \mathrm{~W} / \mathrm{m}^{2} \mathrm{~K}$ \\
Water entrainment constant & 2.0 \\
Molar mass membrane & $1.1 \mathrm{~kg} / \mathrm{mol}^{3}$ \\
Dry density membrane & $1.98 \mathrm{~g} / \mathrm{cm}^{3}$ \\
Cathode activation energy & $66 \mathrm{~kJ} / \mathrm{mol}^{2}$
\end{tabular}

Table 2: List of Fuel Cell Parameters Used

Using the parameters listed in Table 2, the polarisation curve in Figure 6 can be achieved using the fuel cell model developed. Data from [14] is also plotted, and the model shows a good correlation with experimental results. 


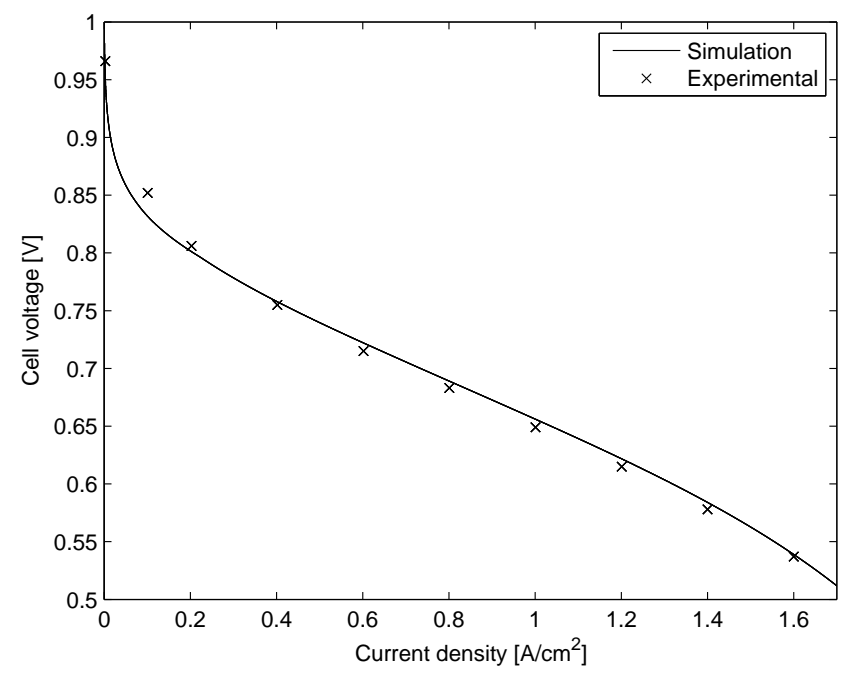

Figure 6: Polarisation curve ascertained from the developed model

The parameters listed in table 3 show the degradation rates used for the Petri-Net model. There is little data in the literature to ascertain all failure mode's interaction upon the voltage of a PEMFC, therefore proposed values are used, based upon the review of experimental data and expert opinion.

The initial setup of the model requires the user to input some starting variables such as; operating temperature (to consider ice formation and excessive heat) and number of startup / shutdown cycles. This data is implicit in placing tokens in the relevant initial places, and inhibitor gates. A dynamic range of inputs can be added to have a varying input (such as temperature) over time. Transition timings for the example in Figure 5 are instant, but for others could be timed or based upon enabling criteria.

\subsection{Results}

The Petri-Net model was programmed in MATLAB on a desktop PC running a dual core $3.10 \mathrm{GHz}$ processor. For all of the individual Petri-Net models, an $A^{T}$ matrix was constructed with a corresponding transition 'firing' script to use the $A^{T}$ matrix information. For each Petri-Net that has an output for which a reduction in performance is noted, a voltage drop count variable is used to store the total amount of degradation in performance due to the failure relationships. Therefore for each output place in a degradation module Petri-Net, a voltage drop figure is added to the overall voltage drop 


\begin{tabular}{lll}
\hline Failure Mode Parameter & Value $\left(\mathbf{V h}^{-1}\right)$ & Ref \\
\hline Incorrect BIP torque & $10^{-3}$ & Proposed \\
Polymer membrane 'creep' & $10^{-5}$ & Proposed \\
Microcrack Fracture & $10^{-2}$ & Proposed \\
OH and OOH radicals \& $\mathrm{H}_{2} \mathrm{O}_{2}$ Degradation & $1.3 \times 10^{-3}$ & {$[15]$} \\
Presence of foreign cationic ions.. & $10^{-4}$ & Proposed \\
Ice Formation & 0.5 & Proposed \\
Fatigue from Relative Humidity Cycling & $1.2 \times 10^{-4}$ & {$[16]$} \\
Excessive Heat Degradation & 0.25 & {$[17]$} \\
Flooding & 0.39 & {$[17]$} \\
Pt Agglomeration and particle growth & $10^{-5}$ & Proposed \\
Pt Elemental loss & $10^{-5}$ & Proposed \\
Pt Migration & $10^{-4}$ & Proposed \\
Pt Contamination & $4.37 \times 10^{-3}$ & {$[18]$} \\
Startup/Shutdown Cycling & $5.333 \times 10^{-5}$ per & {$[19]$} \\
& $c y c l e$ & \\
OH Radicals & $1.3 \times 10^{-3}$ & {$[15]$} \\
Oxide film formation & $10^{-6}$ & Proposed \\
Corrosion leading to release.. & $3.125 \times 10^{-5}$ & {$[20]$}
\end{tabular}

Table 3: List of Degradation Parameters Used

count. Model initialization is commenced via the input of key operating parameters such as operating temperature and potential amongst others. This will place tokens is specific module initial states ready for simulation runs. The in-putted parameters also decide whether key inhibitor places are enabled or not. The model is run either until 5000 hours is reached or a performance drop of $>5 \%$ is experienced.

\subsubsection{Verification of Model}

Startup Shutdown Cycling (SSC) degradation was considered through a review of the literature in this area. Kim, et al.[19] conducted extensive experimentation to reveal the relationship between SSC and degradation of fuel cell performance. Their results show that after 1500 instances of SSC, a drop in performance of $0.08 \mathrm{~V}$ was observed (Figure 7). Therefore per cycle it can be considered that SSC causes a drop in performance of $5.333 \times 10^{-5}$ $\mathrm{V}$. 


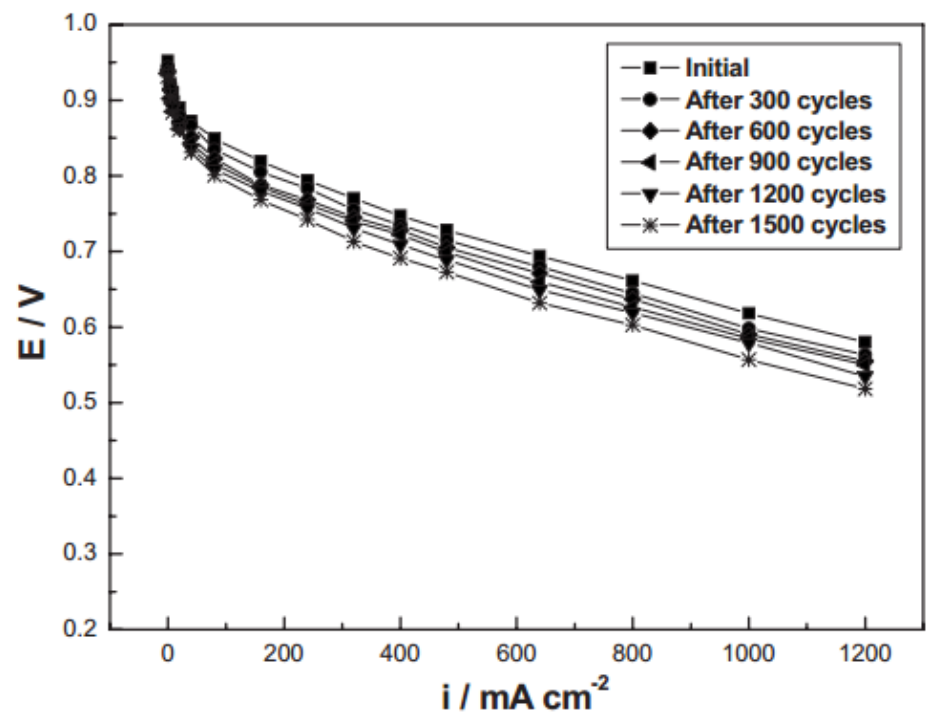

Figure 7: Startup / Shutdown Cycling Tests [19]

The degradation rate was programmed to take affect per SSC, through the transition $T_{1}$ in Figure 8.

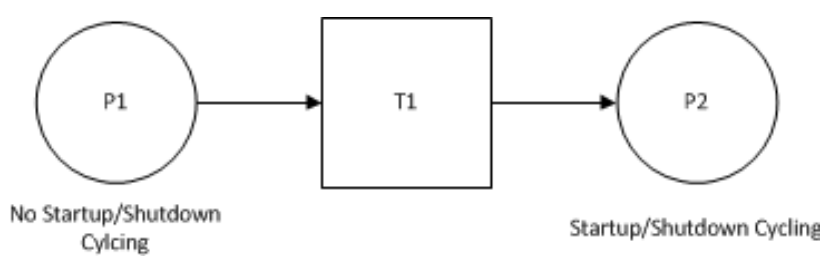

Figure 8: Startup / Shutdown Cycling Petri-Net

Therefore, for each time there is an instance of SSC, a degradation rate of $5.333 \times 10^{-5} \mathrm{~V}$ is applied to a voltage drop count variable.

The results of the Petri-Net model using a SSC degradation module was tested using a polarisation curve model as in Figure 9 . 


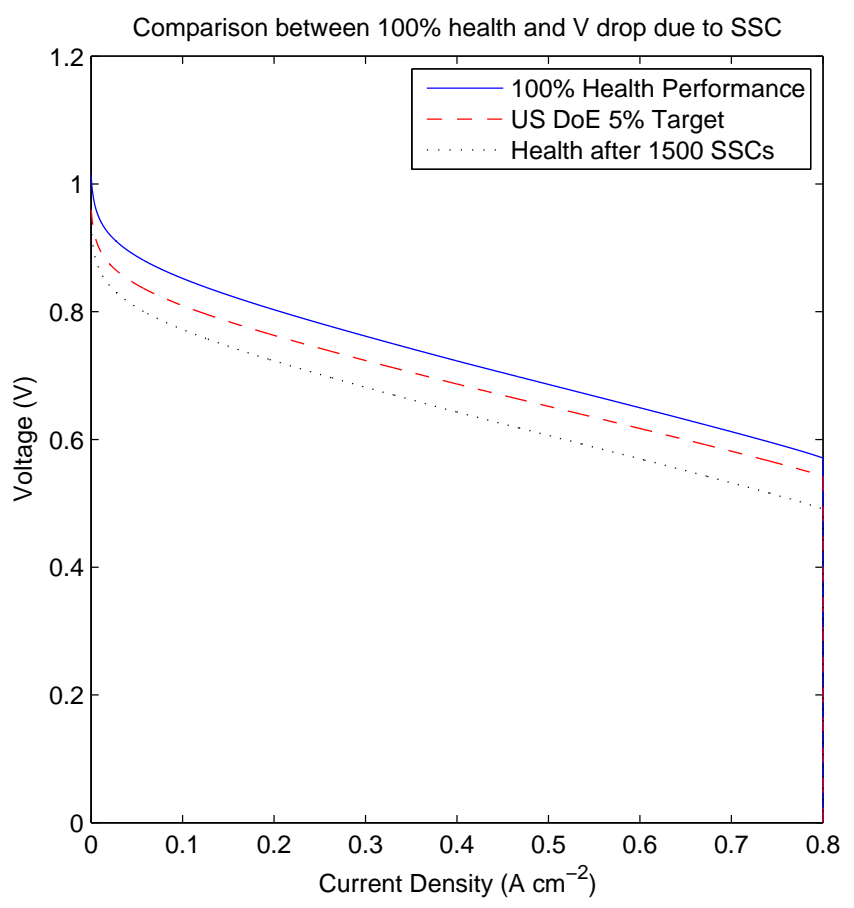

Figure 9: Startup / Shutdown Cycling Petri-Net

The model shows a good replication of the polarisation curve drop observed by Kim, et al.[19] in Figure 7, with the same logic being carried through the entirety of the Petri-Net model. Each failure mode interaction has a voltage degradation value assigned to it, with some acting reversibly dependent upon the state of the system, and some acting as a counter (irreversible).

\section{Conclusions \& Future Work}

The presented work is a step forward in degradation and reliability modelling of PEMFCs. The previous work by the authors leading to this has ensured that the Petri-Net model proposed, is reliably constructed based upon an in-depth, and up-to-date review of PEMFC failure phenomena.

As can be seen in Figure $7 \& 9$, the initial activation range of the polarisation curve does not match up correctly. Due to the fuel cell model developed, this area can be modified due to SSC and take into account degradation in different regions of the polarization curve in future work. 
Future work will include an integration of this degradation model into a PEMFC performance model, capable of plotting polarisation data from key operational inputs. Currently the degradation model needs operating data in the form of initial inputs from the user. That is to say that operating voltage is set from the outset, alongside operating temperature, number of SSCs and other variables. Integration into a PEMFC performance model will allow the performance model to output operational data into the degradation Petri-Net model for its inputs. Then after running the Petri-Net model, the outputs would feed back into the performance model. As the process continues, degradation, and its effect on the performance of the cell can be accurately ascertained. Not only does integration with a PEMFC performance model mean more accurate degradation modelling, it also means that PEMFC operational load levels (such as drive cycles) can be preset, and the degradation due to the fluctuation in load (and therefore temperature etc.) can be considered.

\section{Acknowledgements}

This was supported by the Engineering and Physical Sciences Research Coun-

cil (EPSRC) and the Doctoral Training Centre in Hydrogen Fuel Cells and Their Applications.

\section{References}

[1] S. Solomon, M. D. Qin, Z. Manning, M. Chen, K. B. Marquis, M. Averyt, Tignor, H. Miller, Summary for Policymakers. In: Climate Change 2007: The Physical Science Basis. Contribution of Working Group I to the Fourth Assessment Report of the Intergovernmental Panel on Climate Change, Technical Report, Cambridge University Press, 2007.

[2] D. for Transport, Factsheets: UK transport greenhouse gas emissions, Technical Report, DfT, 2013.

[3] DECC, 2012 UK Greenhouse Gas Emissions, Provisional Figures and 2011 UK Greenhouse Gas Emissions, Final Figures by Fuel Type and End-User, Technical Report, DECC, 2013.

[4] BERR, DTI Energy Price Scenarios in the Oxford Models, Technical Report, BERR, 2006. 
[5] R. Borup, J. Meyers, B. Pivovar, Y. S. Kim, R. Mukundan, N. Garland, D. Myers, M. Wilson, F. Garzon, D. Wood, P. Zelenay, K. More, K. Stroh, T. Zawodzinski, J. Boncella, J. E. McGrath, M. Inaba, K. Miyatake, M. Hori, K. Ota, Z. Ogumi, S. Miyata, A. Nishikata, Z. Siroma, Y. Uchimoto, K. Yasuda, K. I. Kimijima, N. Iwashita, Chemical reviews 107 (2007) 3904-3951. Cited By (since 1996):920.

[6] A. LaConti, M. Hamdan, R. McDonald, W. Vielstich, A. Lamm, H. Gasteiger (Eds.), Handbook of Fuel Cells: Fundemental, Technology, and Applications., volume 3, 2003.

[7] A. Pozio, R. F. Silva, M. D. Francesco, L. Giorgi, Electrochimica Acta 48 (2003) 1543-1549.

[8] P. Rama, R. Chen, J. Andrews, Proceedings of the Institution of Mechanical Engineers, Part A: Journal of Power and Energy 222 (2008) 4214-441. Cited By (since 1996): 4.

[9] L. Placca, R. Kouta, International Journal of Hydrogen Energy 36 (2011) 12393-12405. Cited By (since 1996): 2.

[10] M. Whiteley, L. Jackson, S. Dunnett, in: Proceedings of the 20th Advances i nRisk and Reliability Technology Symposium, Loughborough University, 2013, pp. 75-89.

[11] M. Whiteley, L. Jackson, S. Dunnett, in: Proceedings of the European Safety and Reliability Conference, ESREL, CRC Press, 2013, p. 603.

[12] T. S. Liu, S. B. Chiou, Reliability Engineering and System Safety 57 (1997) 129-142. Cited By (since 1996):61.

[13] C. Wieland, O. Schmid, M. Meiler, A. Wachtel, D. Linsler, Journal of Power Sources 190 (2009) 34-39. Cited By (since 1996): 2.

[14] J. P. Meyers, R. M. Darling, C. Evans, R. Balliet, M. L. Perry, in: ECS Transactions, volume 3, pp. 1207-1214.

[15] K. Teranishi, K. Kawata, S. Tsushima, S. Hirai, Electrochemical and Solid-State Letters 9 (2006) A475-A477. Cited By (since 1996):89. 
[16] M. Fowler, J. C. Amphlett, R. F. Mann, B. A. Peppley, P. R. Roberge, Journal of New Materials for Electrochemical Systems 5 (2002) 255-262. Cited By (since 1996): 20.

[17] J. M. L. Canut, R. M. Abouatallah, D. A. Harrington, Journal of the Electrochemical Society 153 (2006) A857-A864. Cited By (since 1996):85.

[18] S. Y. Ahn, S. J. Shin, H. Y. Ha, S. A. Hong, Y. C. Lee, T. W. Lim, I. H. Oh, Journal of Power Sources 106 (2002) 295-303. Cited By (since 1996): 54 .

[19] J. H. Kim, E. A. Cho, J. H. Jang, H. J. Kim, T. H. Lim, I. H. Oh, J. J. Ko, S. C. Oh, Journal of the Electrochemical Society 157 (2010) B104-B112.

[20] N. Y. Steiner, D. Candusso, D. Hissel, P. Mooteguy, Mathematics and Computers in Simulation 81 (2010) 158-170. Cited By (since 1996): 1.

[21] A. Fly, R. H. Thring, in: Institution of Mechanical Engineers - VTMS 2011, Vehicle Thermal Management Systems Conference Proceedings, pp. 267-277. 